\title{
Identity, Individuality, and Unity
}

\author{
E. J. LOWE
}

In distinguishing between the primary and secondary qualities of bodies in the Essay, Locke notoriously included number amongst the first: ${ }^{1}$

The Qualities then that are in Bodies rightly considered, are of Three Sorts. First, the Bulk, Figure, Number, Situation, and Motion, or Rest of their solid Parts ... These I call primary Qualities. (II, VIII, 23)

Later in the Essay, in the chapter entitled 'Of Number', he goes on to say:

Amongst all the Ideas we have, as there is none suggested to the Mind by more ways, so there is none more simple, than that of Unity, or One: ... every Thought of our Minds brings this Idea along with it. ... For Number applies it self to Men, Angels, Actions, Thoughts, every thing that either doth exist, or can be imagined. (II, XVI, 1)

Just as well-known as Locke's view of number and unity is Berkeley's peremptory repudiation of that view, in his Principles of Human Knowledge. ${ }^{2}$ There Berkeley asserts, concerning number:

That number is entirely the creature of the mind ... will be evident to whoever considers, that the same thing bears a different denomination of number, as the mind views it with different respects. Thus, the same extension is one or three or thirty-six, according as the mind considers it with reference to a yard, a foot, or an inch. ... We say one book, one page, one line; all these are equally units, though some contain several of the others. (Part 1, 12)

${ }^{1}$ See John Locke, An Essay Concerning Human Understanding, P. H. Nidditch (ed.) (Oxford: Clarendon Press, 1975), from which edition all quoted passages are taken.

${ }^{2}$ Quoted passages are taken from George Berkeley, Philosophical Works, M. R. Ayers (ed.) (London: Dent, 1975).

doi:10.1017/S0031819103000329

(C2003 The Royal Institute of Philosophy

Philosophy $\mathbf{7 8} 2003$ 


\section{E. J. Lowe}

And in the next paragraph he continues, concerning unity:

Unity I know some will have to be a simple or uncompounded idea, accompanying all other ideas into the mind. That I have any such idea answering the word unity, I do not find; and if I had, methinks I could not miss finding it; on the contrary it should be the most familiar to my understanding, since it is said to accompany all other ideas. (13)

In his earlier work, An Essay towards a New Theory of Vision, Berkeley expresses similar contempt for Locke's conceptions of number and unity, again making the point that

$[\mathrm{N}]$ umber ... is entirely the creature of the mind ... According as the mind variously combines its ideas the unit varies: and as the unit, so the number, which is only a collection of units, doth also vary. We call a window one, a chimney one, and yet a house in which there are many windows and many chimneys hath an equal right to be called one, and many houses go to the making of one city. (109)

This passage is quoted, with apparent approval, by Frege in The Foundations of Arithmetic-although, of course, Frege should not be taken to concur with Berkeley's suggestion that number is somehow subjective, 'entirely a creature of the mind', in view of Frege's own vehement opposition to psychologism in the philosophy of logic and mathematics. ${ }^{3}$ Frege's agreement with Berkeley extends only as far as the latter's rejection of the view that, as Frege puts it, 'Number is a property of external things' (p. 27). Frege's own view is that

[T] he content of a statement of number is an assertion about a concept. This is perhaps clearest with the number 0 . If I say 'Venus has 0 moons', there simply does not exist any moon or agglomeration of moons for anything to be asserted of; but what happens is that a property is assigned to the concept 'moon of Venus', namely that of including nothing under it. If I say 'the King's carriage is drawn by four horses', then I assign the number four to the concept 'horse that draws the King's carriage'. (p. 59)

Frege himself appeals, on several occasions, to the sort of consideration that Berkeley adduces for rejecting Locke's view of number,

${ }^{3}$ See Gottlob Frege, The Foundations of Arithmetic, trans. J. L. Austin, 2nd edn (Oxford: Blackwell, 1953), p. 33, from which edition all subsequent quoted passages are taken. 
namely that

While looking at one and the same external phenomenon, I can say with equal truth both 'It is a copse' and 'It is five trees', or both 'Here are four companies' and 'Here are 500 men'. (p. 59)

Here is another passage in which he makes the same point:

I am able to think of the Iliad either as one poem, or as 24 Books, or as some large Number of verses. (p. 28)

And here is a third:

The Number $1, \ldots$ or 100 or any other Number, cannot be said to belong to [a] pile of playing cards in its own right, but at most to belong to it in view of the way in which we have chosen to regard it. (p. 29)

In this last case, the suggestion is that what is, from one point of view, one pack of cards is, from another point of view, 52 cards, while from yet another it is four suits, and so on. Even so, there is every indication that Frege is ambivalent about endorsing Berkeley in quite these terms-and not just on account of Berkeley's subjectivism concerning number. Rather, the problem is that it is not hard to discern a latent incoherence in this way of putting things. The incoherence is very near the surface in one of the passages from Frege quoted a moment ago, where he says that 'While looking at one and the same external phenomenon, I can say with equal truth "It is a copse" and "It is five trees". For how can Frege say that one and the same 'external phenomenon' is both one copse and five trees? (Admittedly, the German text reads 'derselben äussern Erscheinung', so that Austin's translation might be criticized for having 'one and the same' instead of just 'the same': but the difficulty is made only marginally less obvious by this amendment.)

What is this 'it' that is somehow both a single copse and five different trees? Frege is clearly aware of the difficulty, for in first presenting the example of the pack of cards he remarks:

[I]f I place a pile of playing cards in [someone's] hands with the words: Find the Number of these, this does not tell him whether I wish to know the number of cards, or of complete packs of cards, or even say of honour cards at skat. To have given him the pile in his hands is not yet to have given him completely the object he is to investigate; I must add some further word-cards, or packs, or honours. (pp. 28-9) 


\section{E. J. Lowe}

Clearly, Frege does not really want to say, on his own account, that one and the same thing can literally be both one and more than one. This is why he admits, later, that

Several examples given earlier gave the false impression that different numbers may belong to the same thing. This is to be explained by the fact that we were there taking objects to be what has number. As soon as we restore possession to the rightful owner, the concept, numbers reveal themselves as no less mutually exclusive in their own sphere than colours are in theirs. (p. 61)

It would seem, then, that Frege's use of the controversial examples is supposed to contribute towards a reductio ad absurdum of the view that numbers are properties of objects. The idea seems to be that if we suppose that numbers are properties of objects, then we shall have to say that different numbers may, with equal legitimacy, be assigned to the same object or objects: that, for example, the same thing may be regarded as one pack of cards or as 52 cards. However, the trouble is that, far from creating a difficulty for philosophers like Locke, the argument, thus understood, rebounds against Frege himself. Berkeley, it should be noted, used the contentious examples to try to show that number is not a 'primary quality' of objects, which they possess independently of the mind: it was no part of his purpose to argue that number is not in any sense a property of objects. But Frege clearly recognizes the incoherence of saying that anything could be at once one thing and more than one thing and that this incoherence does not go away simply by supposing that number is somehow mind-dependent, or a matter of how we 'view' or 'regard' whatever it is to which we are assigning a number. If this is incoherent, however, then it cannot be something to which any philosopher is committed simply in virtue of supposing that number is a property of objects or things, as opposed to Fregean concepts. Rather, the philosopher who takes the former view must clearly just insist that, for example, one pack of cards cannot be identified with 52 different cards, even though it may, of course, consist of 52 different cards.

Frege's own contribution to our understanding of identity statements and his introduction of the notion of a criterion of identity, far from making difficulties for Locke's view of number, actually aid the adherent of that view to rebut the sort of objection that Berkeley advances. Cards and packs of cards are kinds of things that are governed by quite different identity criteria, with the consequence that it makes no sense to say that something could fall under 
both of the sortal concepts card and pack of cards. " 'Sortal' is, of course, a term of Locke's own coinage.) A fortiori, then, something cannot intelligibly be assigned the number one inasmuch as it is regarded as falling under the concept pack of cards and the number 52 inasmuch as it is regarded as falling under the concept card. The upshot of all this is that Frege's frequent appeal to the sort of objection to Locke's view of number that we find in Berkeley is entirely broken-backed.

\section{II}

Frege has related remarks about the notion of unity which are equally unsatisfactory, although in this case we may also take issue with what Locke himself says on the matter. Berkeley, as we saw earlier, expresses contempt for Locke's suggestion that the idea of unity accompanies every other idea, saying that he can find no such idea in his own mind. Part of what Locke is suggesting, clearly, is that everything whatever that exists or could exist is 'one' or a 'unit': that simply in virtue of being self-identical and distinct from anything else, everything has 'unity'. But Frege is just as contemptuous as Berkeley about this suggestion. Sarcastically, he comments:

It must strike us immediately as remarkable that every single thing should possess this property [of being 'one'] ... It is only in virtue of the possibility of something not being wise that it makes sense to say 'Solon is wise'. The content of a concept diminishes as its extension increases; if its extension becomes all-embracing, its content must vanish altogether. It is not easy to imagine how language could have come to invent a word for a property which could not be of the slightest use for adding to the description of any object whatsoever. (p. 40)

This argument, too, backfires on Frege. In fact, in Austin's translation, the first sentence in the passage just quoted looks manifestly absurd: 'It must strike us immediately as remarkable that every single thing should possess this property [of being “one"]'-for what is a 'single' thing if not, precisely, one thing? Singularity and unitariness are, if not identical concepts, at least intimately related. And is the concept of singularity somehow left devoid of content if

${ }^{4}$ I defend this thesis quite generally in my Kinds of Being: A Study of Individuation, Identity and the Logic of Sortal Terms (Oxford: Blackwell, 1989), ch. 4. 


\section{E. J. Lowe}

we suppose that everything exhibits singularity? I ask this question without presuming that such a supposition is correct, for in point of fact I think that the supposition can certainly be challenged, for reasons that I shall give later. My point here is merely that one could not legitimately convict a philosopher of incoherence or vacuity for contending that everything that there is is singular in character. However, it would be unfair to press this objection to Frege simply on the strength of Austin's translation, for the translation is misleading at this point. Frege's original words do not contain anything translatable as 'single' or 'singular'. The sentence in question reads, in German, simply as follows: 'Auffallend wäre zunächst, dass jedes Ding diese Eigenschaft hätte'. Nonetheless, the general point still stands, that it is a poor argument against a putative concept that those who profess to deploy it suppose it to apply to everything whatever. Most philosophers (and, clearly, even Frege himself) would accept that the concept of self-identity applies to everything whatever, but they cannot be convicted on that account of evacuating the concept of all content.

Frege supplements the poor argument that I have just criticized by urging that 'Solon was one' does not make sense in anything like the way that 'Solon was wise' does, because the former is not 'intelligible on its own in isolation' (p. 40). He goes on:

This is even clearer if we take the plural. Whereas we can combine 'Solon was wise' and 'Thales was wise' into 'Solon and Thales were wise', we cannot say 'Solon and Thales were one'. But it is hard to see why this should be impossible, if 'one' were a property both of Solon and of Thales in the same way that 'wise' is. (pp. 40-1)

However, the natural and correct response to this is to point out that being one is necessarily a property only of single things, whereas Solon and Thales are not a single thing: rather, they are two things, whence they possess the property of being two. (This will become clearer shortly, when we come to discuss pluralities.) It remains the case that we can still say, quite truly, 'Solon and Thales were each one', while also saying, with equal truth, 'Solon and Thales (together) were two'. The fact that Solon and Thales were two, even though Solon was not two and Thales was not two, is no more puzzling than the fact, say, that Smith and Jones moved the piano, even though Smith did not move the piano and Jones did not move the piano (the piano being too heavy for one person to move). Any oddity that attaches to sentences like 'Solon was one' and 'Solon and Thales were two' is, I suggest, purely pragmatic in character, 
arising from the fact that the applicability of the predicate is already apparent from the grammatical form of the subject, so that such sentences appear to be stating the obvious. However, what is obvious is not precluded from being both meaningful and true.

Even so, the suggestion that everything has the property of being one-that everything is one thing-might be questioned on the ground that the numbers, including the number one, are used in counting things, but that it makes no sense to count things as such, since we can only count things of specifiable sorts or kinds. This, indeed, was the implication of Frege's remarks, quoted earlier, concerning the pile of cards, and the indeterminacy of the instruction to 'Find the Number of these'. One needs to be told whether one is to count the packs, or the cards, or the honour cards, or whatnot. However, while there is something that is right about what Frege says in this connection, there is also something that is wrong or at least misleading. It is wrong, and obviously so, to suppose that one cannot include things of many different kinds in a single count. I could quite coherently ask someone to count the packs and the cards, for instance. If there were 52 cards and four complete suits, then the answer to the question 'What is the number of packs and cards?' would be 53. This would be an odd question to ask, but not an unintelligible or unanswerable one. Similarly, it would make perfectly good sense to ask how many children and books there were in a certain classroom. On the other hand, it is not so easy to make sense of an instruction, say, to count the cards and the honour cards, simply because each honour card is a card and we presumably ought to avoid double-counting. Even so, given a suitable disambiguation of this instruction, it too could be coherently carried out. Indeed, on the most reasonable interpretation of it, the answer would seem to be, in the case envisaged, 52-in other words, that there are just as many cards and honour cards as there are cards. ${ }^{5}$

Where problems of principle arise in matters of counting is where we are expected, somehow, to include in the count items that do not qualify as single things. For many philosophers-including, it would appear, Locke-no such problem can ever arise, precisely because, in their view, everything whatever that exists or could exist is a single thing. However, as I have already indicated, this view can certainly be challenged. And, of course, anyone who does challenge

For a recent repudiation of the thesis that it is somehow incoherent to inquire, without qualification, into 'the number of things', see Peter van Inwagen, 'The Number of Things', Philosophical Issues 12 (2002), pp. $176-96$. 


\section{E. J. Lowe}

it will not be vulnerable to Frege's objection, for what it is worth, that it is vacuous to attribute 'oneness' to objects because this is a property that everything would have to have.

But, it will now be asked, how can it make sense to say that something might fail to be one, singular, or unitary-fail to possess oneness, singularity, or unitariness? If the question were how some thing could fail to be one, singular, or unitary, then I might indeed be inclined to dismiss as incoherent the thought that there could be any such failure, because the concept of a 'thing' seems already to have the notion of singularity or unitariness built into it. However, while 'Everything is something' is, apparently, a trivial truth of logic, 'Everything is some thing' looks like a more substantive metaphysical claim.

One reason for denying that everything is a thing is that the world, as well as containing individual things, contains pluralities of things - and a plurality of things is not a single thing. Indeed, if we are to take seriously Locke's suggestion that number is a property of things, then, clearly, the only number that can be assigned to a single thing-Berkeley's objection having been repudiated-is one. And this means, of course, that numbers other than one can only be assigned to more than one thing - that is, to pluralities of things. We say, for example, and quite properly, that the planets are nine in number, as are the muses. In the sentence 'The planets are nine', the subject term, 'the planets', refers plurally to Mercury, Venus, Mars, Earth, Jupiter, Saturn, Uranus, Neptune and Pluto, and the predicate attributes the property of being nine to that plurality. We should not be misled here by the fact that the expression 'that plurality' is grammatically singular in form. This is a mere idiosyncrasy of idiom and does not signify that there is some further thing, 'the plurality of the planets', in addition to the planets themselves. When I suggest that pluralities provide a plausible exception to the thesis that 'Everything is a thing', I mean just this: pluralities exist, and yet, manifestly, are not single things. For instance, the planets exist, and yet are not one thing. To the extent, then, that the socalled universal quantifier, expressed in English by means of the word 'everything', ranges at least over what exists, it ranges over pluralities as well as over single things, given that pluralities exist. Hence it is true to say that not everything is a thing.

But this is not the only reason for denying that everything is a thing. Pluralities of individual things can at least be assigned a number. The planets are nine and the books of the Iliad are 24. To avoid potential confusion, let us henceforth use the term 'entity' to denote anything whatever that does or could exist, whether or not it 
is an individual thing. Then, I want to say, there are or could be entities to which numbers cannot even in principle be assigned. One of the most plausible supporting examples for this thesis is provided by quantities of matter, especially if these are conceived as homogeneous and infinitely divisible. Such a quantity of matter might seem to be a good candidate for being a plurality-but it cannot, it seems, be a plurality of individual things. This is because, although it includes distinct entities, each of the entities that it includes is in turn a (lesser) quantity of matter. If all quantities of matter were ultimately made up of indivisible atoms-which may be something like the truth as far as the actual physical world is concerned-then they would indeed be very good candidates for being pluralities, namely, pluralities of atoms. (Locke himself was sympathetic to atomism, of course.) But it doesn't really make sense, it would seem, to talk of a plurality which is not a plurality of individual things, since the concept of a plurality is tied to that of number and where there are no individual things no number can meaningfully be assigned.

We need, it would seem, a new ontological term to apply to entities such as our hypothetical quantities of homogeneous and infinitely divisible matter. We could call them, perhaps, dividuals. ${ }^{6}$ Dividuals cannot be assigned numbers-neither the number one nor any greater number. They are not single things, nor are they pluralities. Yet dividuals may be distinguished: the quantity of matter in one bowl may be wholly distinct from the quantity of matter in another bowl. Any proper part of a quantity of matter is a quantity of matter which is distinct from the whole of which it is a part and distinct, too, from other proper parts of that same whole. To avoid any misunderstanding here, it must be emphasized that a quantity of matter is not the same as a piece of matter. A piece of matter is an individual thing, composed of matter that is gathered together to make a single connected whole. That same quantity of matter could be divided and separated in infinitely many different ways, without thereby ceasing to exist. It would continue to exist even if it were scattered across the entire universe. A piece of matter, on the other hand, continues to exist only so long as the quantity of matter composing it remains gathered together.

${ }^{6} \mathrm{I}$ am not sure whether this term has been used by anyone else before me, but I first used it myself in my 'Primitive Substances', Philosophy and Phenomenological Research 54 (1994), pp. 531-52. See also my The Possibility of Metaphysics: Substance, Identity, and Time (Oxford: Clarendon Press, 1998), p. 161. 


\section{E. J. Lowe}

I have just said that numbers-and here I mean cardinal numbers, quite generally—cannot be assigned to dividuals. But there is, of course, a perfectly good sense in which numbers can be assigned to dividuals, such as quantities of matter. For we can say, concerning a certain quantity of matter, how much of it there is and assign a number to this amount, given an appropriate choice of units for the purposes of measurement. (Here we may in principle need recourse not just to integral or rational numbers but to real numbers, given the hypothesized infinite divisibility of quantities of matter.) So, for example, if we use kilogrammes as our units of mass, we may say that there are 2.35 kilogrammes of matter in the bowl. However, it is important to appreciate that in thus assigning a number to the quantity of matter in the bowl, we are focusing on just one physical property of the matter, its mass. After all, we might alternatively want to assign a number to the volume of the quantity of matter rather than to its mass. So, what we are measuring and thus assigning numbers to is not really the mere quantity of matter as such but, rather, certain of its properties, such as its mass or its volume. It would seem that there are and can be no 'units' for measuring how much matter, as such, a quantity of matter is. And, in any case, it is clear that the sense in which we can assign numbers to quantities of matter is completely distinct from that in which we can assign numbers to pluralities of individual things and in no way undermines the ontological distinction that I just have proposed between individuals and dividuals.

\section{III}

So far, I have mainly been concerned to defend the Lockean view that number is a property of objects against Frege's view that number is a property of concepts. (Of course, in this connection it is important to appreciate that Frege thinks of concepts as being objective and mind-independent, and hence as being quite distinct from the psychological entities that Locke and Berkeley call 'ideas'.) Even the most ardent supporter of Frege must surely concede that Frege's view on this matter is relatively counter-intuitive-and, after all, he himself implicitly pays tribute to the intuitiveness of the Lockean view in spending so much effort to convince us of its falsehood. One consideration which, as a passage quoted earlier indicates, seems to have weighed heavily with Frege is the apparent problem confronted by the Lockean view in the case of the number 0 . As Frege remarks, "If I say "Venus has 0 moons", there simply 
does not exist any moon or agglomeration of moons for anything to be asserted of'. In other words, even if we can maintain that the property of being one is a property that an object can (and indeed must) possess and that numbers greater than one can be possessed by pluralities of objects, it seems that there plainly can't be any object that possesses the property of being zero. By contrast, the concept moon of Venus clearly can have assigned to it the property of 'including nothing under it', which is how Frege recommends us to think of something's having the number 0 . Moreover, this way of thinking of the bearers of numerical properties famously enables him to forge a link between distinctions of number and quantificational distinctions, as expressed by words like 'all', 'some', and 'none'. This in turn enables him to observe that

$[\mathrm{E}]$ xistence is analogous to number. Affirmation of existence is in fact nothing but denial of the number nought. Because existence is a property of concepts the ontological argument for the existence of God breaks down. (p. 65)

How can an adherent of Locke's view of number respond to these points? Well, first of all, it may be pointed out that, although it comes very naturally to a mathematician to think of 'zero' as denoting a number, most ordinary folk would consider it at best a bad joke to be told that, say, there is a number of pound notes in a sealed envelope that has just been given to them, when in fact the envelope is empty. The response 'Well, I did say a number of pound notes, and nought is a number' would do nothing to pacify the irate recipient. The introduction of the zero symbol was undoubtedly an important landmark in the history of mathematics, but we should not assume that its utility in calculation is dependent upon its actually denoting some object or expressing some property. In particular, we should not uncritically accept the currently standard view that 'zero' denotes the empty set, because it is far from clear that the notion of such a set really makes sense. All that we are ever informed about the empty set is that it is (1) a set, (2) has no members, and (3) is unique amongst sets in having no members. However, there are very many things that 'have no members', in the set-theoretical sense-namely, all non-sets. It is perfectly clear why these things have no members, for they are not sets. What is unclear is how there can be, uniquely amongst sets, a set which has no members. We cannot conjure such an entity into existence by mere stipulation-although this is, in effect, what Frege himself does with respect to the number nought.

Frege defines the number nought as follows: 


\section{E. J. Lowe}

Since nothing falls under the concept 'not identical with itself', I define nought as follows: 0 is the Number which belongs to the concept 'not identical with itself'. (p. 87)

But what entitles him to suppose that anything exists which satisfies this definition? Here he can appeal to another definition, namely, his general definition of Number:

[T] he Number which belongs to the concept $F$ is the extension of the concept 'equal to the concept $F$ ' (pp. 79-80),

where, as he has already explained, a concept $F$ is 'equal' to a concept $G$ just in case it is possible to 'correlat[e] one to one the objects which fall under the one concept with those which fall under the other' (p. 79). From this and the previous definition it follows that 0 is the extension of the concept "equal to the concept "not identical with itself"'. But what entitles Frege to suppose that the "extension' of this concept exists? Well, the notorious Axiom V of Frege's Grundgesetze der Arithmetik will give him what he needs, since that axiom says, in effect, that the extension of the concept $F$ is identical with the extension of the concept $G$ if and only if all and only the objects which fall under $F$ also fall under $G$-and this in turn implies that every concept has an extension. But that, of course, is what brings about the downfall of Axiom V, because it thereby falls victim to Russell's paradox.?

However, the so-called 'neo-logicists' think that Frege has the resources with which to proceed in another and more satisfactory way, by appealing not to Axiom $\mathrm{V}$ but to his own criterion of identity for cardinal numbers-a criterion which now often goes by the name of 'Hume's principle' and is expressible in the form 'The number which belongs to the concept $F$ is identical with the number which belongs to the concept $G$ if and only if it is possible to correlate one to one the objects which fall under the concept $F$ with those which fall under the concept $G$ '. Then he can 'prove' the existence of the number nought by taking both ' $F$ ' and ' $G$ ' in Hume's principle to stand for 'not identical with itself', to give us as a supposedly true equivalence "The number which belongs to the concept "not identical with itself" is identical with the number which belongs to the concept "not identical with itself" if and only if there are exactly as many non-self-identical things as there are non-selfidentical things'. Since what stands on the righthand side of this equivalence is an analytic and indeed logical truth, what stands on

7 See, e.g., Crispin Wright, Frege's Conception of Numbers as Objects (Aberdeen: Aberdeen University Press, 1983), p. 155. 
the left is true, given that the equivalence itself is true. But what stands on the left entails 'There is something that is identical with the number which belongs to the concept "not identical with itself"'. However, since Frege has just defined nought as the number which belongs to the concept 'not identical with itself', it follows from this that there is something that is the number noughtin other words, that the number nought exists. ${ }^{8}$ What is remarkable is that Frege imagined that he could, one way or another, pull this particular rabbit out of the hat so shortly after having criticized adherents of the ontological argument for doing something very similar in the case of God.

The proper response to all of this, it seems to me, is to deny Hume's principle, at least in its Fregean formulation. I am happy to accept an alternative formulation, to the effect that pluralities whose members are one-one correlatable are equinumerous, or possess the same number. Taking a single object to be the limiting or degenerate case of a plurality, this allows us to say that every single object possesses the number one. But since the notion of a 'null' plurality is a manifest absurdity, we are not committed to existence of 'the number nought'. A particularly objectionable feature of Hume's principle in its Fregean formulation, from an ontological point of view, is that it entails (in conjunction with a definition of 'successor') not only the existence of the number nought, as defined by Frege, but the existence of infinitely many cardinal numbers, namely, all the successors of the number nought. Some philosophers clearly think that this is, on the contrary, a great virtue of Frege's version of Hume's principle, since it gives them mathematical objects on the cheap. But in serious ontology there is no such thing as a free lunch. (Of course, it should also be remarked that invoking the name of Hume in this connection is highly misleading, in any case, since Hume himself did not appear to have anything like Frege's criterion of identity for cardinal numbers in mind when he wrote the passage cited by Frege, namely, that 'When two numbers are so combined as that the one has always an unit answering to every unit of the other, we pronounce them equal' (p. 73). ${ }^{9}$ Hume seems to have in mind, rather, a method for determining, for arbitrarily chosen natural numbers $n, n^{\prime}, m$, and $m^{\prime}$, whether or not $(n+$ $\left.n^{\prime}\right)=\left(m+m^{\prime}\right)$, e.g., whether or not $(7+5)=(9+3)$.)

${ }^{8}$ Precisely this proof may be found in Wright, Frege's Conception of Numbers as Objects, pp. 158-9.

${ }^{9}$ See David Hume, A Treatise of Human Nature, ed. L. A. Selby-Bigge and P. H. Nidditch (Oxford: Clarendon Press, 1978), Bk I, Part III, sect. 1 [p. 71]. 


\section{E. J. Lowe}

But what are we to say about the linkage, forged by Frege, between numerical notions and the notions of quantification and existence? In particular, if we reject his view of number, should we also reject his view of the meaning of existential statements? According to Frege, existence is a 'second-level' concept. Thus, in 'On Concept and Object' he remarks: ${ }^{10}$

I have called existence a property of a concept. How I mean this to be taken is best made clear by an example. In the sentence 'there is at least one square root of 4', we have an assertion ... about a concept, square root of 4; viz. that it is not empty. (pp. 48-9)

And a little later:

I do not want to say it is false to assert about an object what is asserted here about a concept; I want to say it is impossible, senseless, to do so. The sentence 'there is Julius Caesar' is neither true nor false but senseless. (p. 50)

However, 'Julius Caesar exists' seems to make perfectly good sense and is most improbably analysed as meaning anything like, say, 'There is at least one thing that is identical with Julius Caesar', even if it entails the latter. That is to say, it is most implausible to suggest that in affirming Julius Caesar's existence we mean to affirm, about the concept identical with Fulius Caesar, that it is 'not empty'. In any case, in what does the 'non-emptiness' of such a concept consist? Surely, simply in the being of something which 'falls under it'. But all that can 'fall under it' is an object-in this case, Julius Caesar. So the non-emptiness of this particular concept can only consist in the being — the existence-of Julius Caesar. More generally, far from its being the case that existence is to be explained in terms of the 'nonemptiness' of concepts, quite the reverse seems most plausiblethat the 'non-emptiness' of concepts, which is a technical rather than a common-sense notion, calls out for explanation in terms of the existence of objects falling under them. The proper conclusion to draw is that existence, like number, is a property of objects. The fact that these properties are very unlike commonplace empirical properties, such as the physical properties of colour and shape, is neither here nor there. The same is true of such 'formal' properties as the property of being self-identical, the property of being an object and, indeed, the property of being a property.

${ }^{10}$ See Translations from the Philosophical Writings of Gottlob Frege, 2nd edn, P. Geach and M. Black (eds.) (Oxford: Blackwell, 1960). 


\section{Identity, Individuality, and Unity}

\section{IV}

Where now does this leave us with regard to the key ontological notions of identity, individuality and unity mentioned in the title of this paper? The general position that I wish to recommend may be summarized as follows. Not every entity that does or could exist is an individual object of some kind, although every entity is necessarily self-identical. An individual object is an entity which, quite literally, counts as one entity of some kind, in order to do which it must possess unity. Only unitary entities can qualify as individual or single objects, capable in principle of being enumerated along with other such objects. There are or could be entities which lack unity, which we might call dividuals, as opposed to individuals. Putative examples of such entities are quantities of homogeneous and infinitely divisible matter. This distinction between dividuals and individuals is reflected in ordinary language in the distinction between mass nouns and count nouns or, in an alternative terminology, between mass terms and sortal terms.

Both dividuals and individuals may have parts, but the parts of dividuals are further dividuals and need not be unified in any way. In contrast, a composite individual-one that has proper partsmust have parts that are integrated according to some principle that is characteristic of individuals of its kind. For example, an animal, such as a tiger, is a composite individual of such a kind that it must have organic parts that are spatially and causally connected so as to enable them to function in the right sort of way to sustain the life of the individual animal that they compose. Typically, the parts of a composite individual of a given kind are individuals of various other kinds - as, for example, the parts of a tiger include such things as its heart, eyes, stomach, legs, and so forth.

Only individuals are countable. Each individual counts as onethat is, as one thing of its kind. No individual can count as more than one. Only pluralities of individuals can count as more than one. Although a composite individual, such as an individual pack of cards, may have many parts, the composite individual itself can still only count as one. What counts as more than one in such a case is not the composite individual but a plurality of its parts. Since the parts of a composite individual may themselves have parts, which are also parts of the composite individual in question (since parthood is transitive), there may be many different pluralities of parts that may be said to compose the same individual. Thus, for example, an individual tiger is composed by its various organs and limbs, but is also composed by a plurality of atomic and sub-atomic 


\section{E. J. Lowe}

particles. The different pluralities composing the same composite individual may very well have different numbers assignable to them. But, once more, the composite individual itself may only be assigned the number one.

It is possible, at least in principle, for an individual to be composed of dividuals - as, for example, a piece of homogeneous and infinitely divisible matter would be composed by quantities of homogeneous and infinitely divisible matter. Dividuals, such as quantities of homogeneous and infinitely divisible matter, possess self-identity and are determinately distinct from one another and from all individuals. And yet, as we have seen, they lack unity and consequently are uncountable-not in the sense that they are uncountably many, like the real numbers, but rather in the sense that cardinal numbers are not assignable to them. They cannot comprise pluralities in the way that individuals do. Locke was right to say that number is a property of objects. But he was wrong to assert that 'Number applies it self to Men, Angels, Actions, Thoughts, every thing that either doth exist, or can be imagined' (II, XVI, 1). For number does not apply to dividuals and yet dividuals can at least be imagined. ${ }^{11}$

University of Durham

${ }^{11}$ I am grateful for comments received when this paper was presented at the Royal Institute of Philosophy symposium on 'Being One', held at the University of Manchester in December 2002. 